\title{
Microwave heating of carbon-based solid materials
}

\author{
Teawon Kim, Jaegeun Lee and Kun-Hong Lee \\ Department of Chemical Engineering, Pohang University of Science and Technology, Pohang 790-784, Korea
}

\section{Article Info}

Received 3 December 2013

Accepted 19 December 2013

*Corresponding Author

E-mail: ce20047@postech.ac.kr

Tel: $+82-54-279-2271$

\section{Open Access}

DOI: http://dx.doi.org/

10.5714/CL.2014.15.1.015

This is an Open Access article distributed under the terms of the Creative Commons Attribution Non-Commercial License (http://creativecommons.org/licenses/ by-nc/3.0/) which permits unrestricted non-commercial use, distribution, and reproduction in any medium, provided the original work is properly cited.

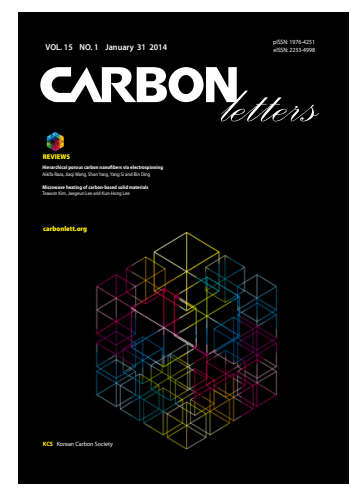

http://carbonlett.org

pISSN: $1976-4251$

elSSN: 2233-4998

Copyright $\odot$ Korean Carbon Society

\begin{abstract}
As a part of the electromagnetic spectrum, microwaves heat materials fast and efficiently via direct energy transfer, while conventional heating methods rely on conduction and convection. To date, the use of microwave heating in the research of carbon-based materials has been mainly limited to liquid solutions. However, more rapid and efficient heating is possible in electron-rich solid materials, because the target materials absorb the energy of microwaves effectively and exclusively. Carbon-based solid materials are suitable for microwave-heating due to the delocalized pi electrons from sp2-hybridized carbon networks. In this perspective review, research on the microwave heating of carbon-based solid materials is extensively investigated. This review includes basic theories of microwave heating, and applications in carbon nanotubes, graphite and other carbon-based materials. Finally, priority issues are discussed for the advanced use of microwave heating, which have been poorly understood so far: heating mechanism, temperature control, and penetration depth.
\end{abstract}

Key words: microwave, carbon nanotube, carbonization, graphite, heat treatment, Maxwell-Wagner-Sillars polarization, penetration depth

\section{Introduction}

Microwaves are a part of the electromagnetic spectrum with frequencies ranging from $300 \mathrm{MHz}$ to $300 \mathrm{GHz}$, lying between infrared and radio frequencies. Microwave technologies were developed rapidly during and after the Second World War for radar and communication uses. These days, microwaves are extensively used for wireless communications, such as long term evolution; for major wireless local area network standard (Wi-Fi); space craft communication and radar applications like global positioning system; and air traffic control. In addition to the radar and communication uses, microwaves are also widely used for heating. Foods are rapidly and conveniently heated by a microwave oven at home, and a variety of materials are heated at industries and laboratories using microwaves.

Microwave heating provides several advantages over conventional (firing or resistive) heating, most of which come from the way energy is delivered. Microwaves can deliver their energy directly to target materials by radiation at the speed of light without conduction or convection, the main processes of energy transfer in conventional heating. Thus, microwave heating is much faster than conventional heating, and selective heating is possible without interaction between the microwaves and their surroundings.

Research on the microwave heating of carbon-based materials can be classified into two categories depending on the phase of microwave absorber. One is solution heating, represented by microwave-assisted organic synthesis (MAOS) and the other is solid heating, whose main targets are solid state carbons and metals. Solution and solid heating differ greatly, both in the heating mechanism and the accompanying reactions.

The difference in the heating mechanism for a solution and a carbon-based solid is shown in Fig. 1. Microwave heating of a solution is mainly related to the dipole rotation of polar solvent molecules. However, in electron-rich solids which have no freely-rotatable dipoles, like carbon-based solids, it is the motion of electrons that generates heat, through joule heat- 


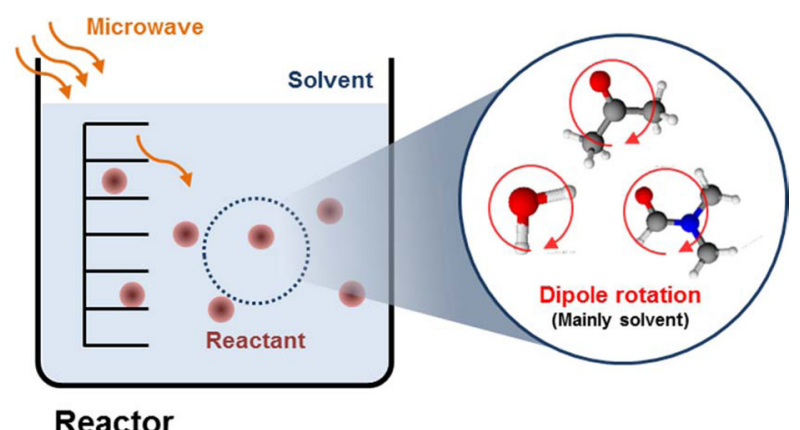

(a) Solution

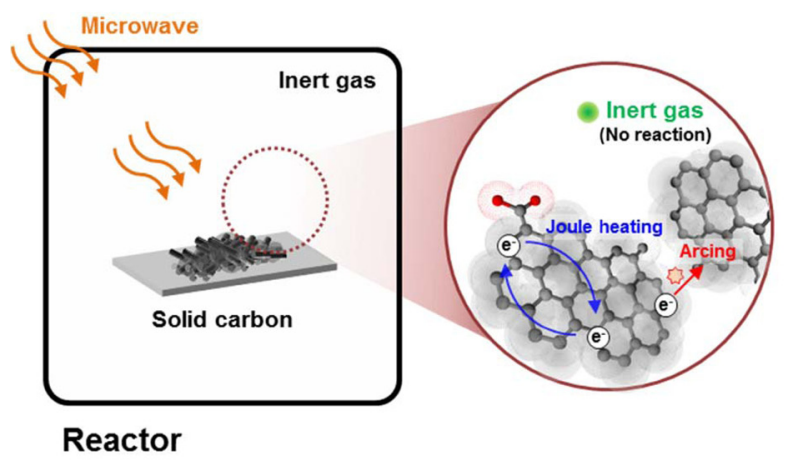

(b) Carbon-based solid

Fig. 1. Mechanism of microwave heating for (a) polar solution and (b) solid carbon.

ing within the grain, or arc generation at phase boundaries.

Microwave heating of solid state carbon-based materials has distinct merits, but they have scarcely been reported, while over 800 papers were published about MAOS in 2007 alone [1]. The purpose of this review is to introduce the microwave heating of carbon-based solid materials, including carbon nanotubes (CNTs), graphite, and others. Also, issues crucial to the advanced research of microwave-carbon heating are discussed.

\section{Theory}

The mechanism of microwave heating varies according to the interaction between the microwaves and target materials. In this section, the heating mechanisms and the characteristics of solution heating and carbon-based solid heating will be covered for an obvious contrast. Before that, polarization and conductivity will be dealt with, since they play important roles in the microwave heating of both solutions and carbon-based solids.

\subsection{Polarizations under microwaves}

When a dielectric material, whose charged particles can't move freely, is exposed to an external electric field, the electric charges cause dielectric polarization, which arises from the displacement of charges from their average equilibrium position. This polarization can be categorized as follows: 1) electronic polarization by displacement of electrons from the nuclei, 2)

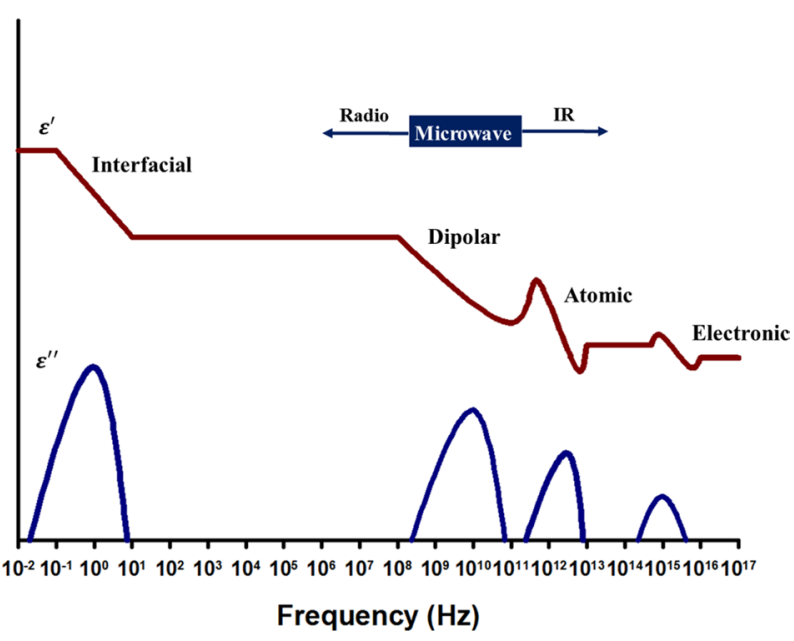

Fig. 2. Frequency dependence of polarizations [2].

atomic polarization by displacement of atomic nuclei, 3) dipolar polarization by reorientation of molecules which have permanent dipoles, and 4) interfacial polarization by accumulation of relatively mobile charges at grain/phase boundaries or surfaces.

Microwaves are a kind of electromagnetic wave, and consequently, the direction and the magnitude of their electric field changes continuously with time, so the polarization they induce is also changed with time. In general, polarization has a phase lag with the electric field oscillation because a material's polarization does not respond instantaneously to an applied field. Therefore, permittivity $(\varepsilon)$, which describes the electric field flux generated by polarization, is usually expressed as a complex form $\left(\varepsilon^{\prime}+\mathrm{i} \varepsilon^{\prime \prime}\right)$ to show the magnitude and the phase of polarization at the same time. Here, the real part of permittivity $\left(\varepsilon^{\prime}\right)$ is related to the stored energy within the medium and the imaginary part of the permittivity $\left(\varepsilon^{\prime \prime}\right)$ is related to the energy dissipated as heat.

When the frequency of an electric field oscillation is increased over a certain point, some polarization stops contributing to the total polarization because there is an increasing phase lag between the electric field oscillation and reorientation of the polarization. In this case, the real part of the permittivity-decreases while the imaginary part of the permittivity decreases, which means the dissipation of energy in the form of heat increases.

The frequency dependence of dielectric permittivity is shown in Fig. 2. Electronic polarization and atomic polarization don't contribute to microwave absorption because they start to have phase lag at a frequency higher than the microwave frequency. Generally, interfacial polarization occurs far below the microwave frequency, but the peak frequency of dielectric loss factor of interfacial polarization can vary considerably according to the conductivity and dielectric properties of the material. Thus, interfacial polarization as well as dipolar polarization are considered to be the polarizations involved in microwave heating.

\subsection{Conductivity under microwaves}

When charged particles can move freely within the material, electric conduction can be generated by charged particles, which 
obtain kinetic energy from the external electric field. Typical examples are the movement of electrons in metals or semiconductors and the movement of ions in ionic liquids.

The movement of charged particles generates heat by collisions. Electrons collide with atomic ions composing the body of conductors or semiconductors. Ions in an aqueous solution collide with neighboring molecules or atoms. Heat is generated as a consequence of the collisions, a process commonly called Joule heating.

\subsection{Microwave heating of solutions}

Microwave heating of a solution is explained by dipolar polarization and ionic conduction. Most solvents including water, dimethylformamide, tetrahydrofuran and ethanol have permanent dipoles. When a microwave is applied, the dipoles rotate with a delay to the change of the electric field, which causes friction and heat. In addition, the solution is also heated by ionic conduction when ions exist.

As a result, most reactions can be carried out using polar solvents even when the microwave absorbance of the reactant is poor. On the other hand, the method has some limitations, as follows: 1) most of the microwave energy used for the heating of polar solvents is dissipated, and 2) there is no macroscopic difference in the distribution of temperature within the reactor, while the absorption of microwave energy may be selective.

\subsection{Microwave heating of carbon-based solids}

In the case of carbon-based solids which have few or no freely rotating dipoles, microwave heating can't be explained as above. Instead, the interaction between microwaves and electrons is important. Microwave heating of carbon-based solids is mainly explained by interfacial polarization (so called MaxwellWagner-Sillars [MWS] polarization). In addition, carbon-based solids possess semiconducting features because of delocalized pi-electrons in the graphitic region [3,4], so Joule heating also plays an important role in the heating of carbon-based solids by microwave.

In these cases, unlike solution heating, microwave heating is very efficient and selective because the microwave energy is solely absorbed by the target material.

\section{Microwave heating of CNTs}

CNTs have excellent electrical properties resulting from $\mathrm{sp2-}$ networks of carbon atoms. The number of free electrons which can migrate freely over the whole of the layer is about one per each carbon atom [4]. The free electrons enable CNTs to absorb microwave energy considerably and to be heated effectively by microwaves.

The microwave absorbing property of CNTs was measured by Grimes et al. [5] for the first time in 2000. Complex permittivity of 0-23 weight percent single-wall CNTs (SWCNTs) dispersed in poly-ethylmethacrylate composites was measured in the frequency range from $500 \mathrm{MHz}$ to $5.5 \mathrm{GHz}$ as shown in Fig. 3. With 23 weight percent of SWCNTs, the imaginary part of the complex permittivity was increased by a factor of 1200 at

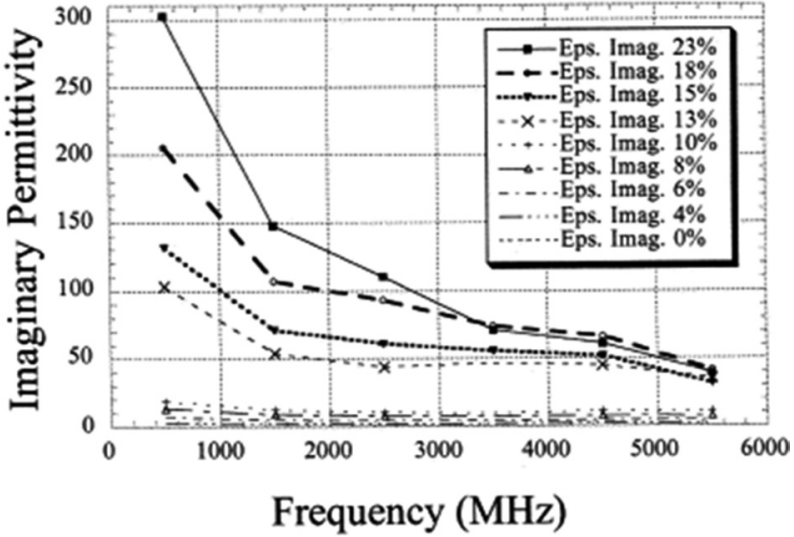

Fig. 3. Imaginary $\left(\varepsilon^{\prime \prime}\right)$ part of permittivity spectra of polymer composites with 0-23 wt $\%$ of single-wall carbon nanotube [5] Reprinted with permission from [5]. Copyright $\odot 2000$, Elsevier

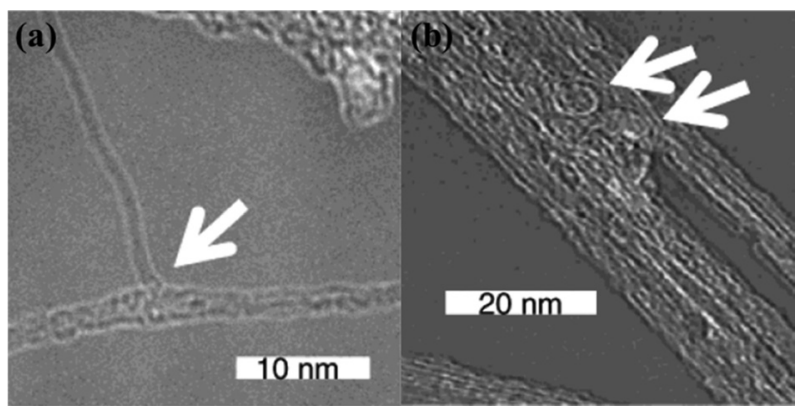

Fig. 4. Transmission electron microscope images of vertically aligned carbon nanotubes after microwave treatment. (a) Fused nanotubes and (b) looped nanotubes after microwave irradiation [6].

Reprinted with permission from [6]. Copyright $\odot$ 2003, American Chemical Society.

$500 \mathrm{MHz}$ and measured over 100 at $2.45 \mathrm{GHz}$.

In 2003 Imholt et al. [6] reported various observations of microwave-CNTs reaction with temperature measurement. Microwave irradiation $(2.45 \mathrm{GHz}, 700 \mathrm{~W})$ on HiPco-generated SWCNTs showed strong microwave absorption with light emission, heat release, outgassing and nanotube reconstruction. The temperature reached $2000^{\circ} \mathrm{C}$ during the reaction and $\mathrm{H}_{2}$ expulsion was observed by a residual gas analyzer. Fig. 4 displays transmission electron microscope images of CNTs after microwave irradiation showed welded and looped nanotubes which were not present in the original HiPco SWCNTs.

Among the various applications of microwave heating of CNTs, CNT/polymer welding is the most actively researched area. Unlike other CNT/polymer composite making techniques such as solution mixing, melt mixing and in-situ polymerization [16], microwave welding gives several advantages.

The first advantage is that microwave welding can be done within a few minutes [7-11,13-15]. Specifically, Wang et al. [8] reported CNTs subsided into a poly(ethylene terephthalate) (PET) substrate after only $1 \mathrm{~s}$ of microwave irradiation. A second advantage is the selectiveness of the heating. Because the microwave absorbance of most polymers is negligible, only CNTs absorb the microwave energy and are heated [2]. So, welding can be performed without significantly affecting the 
Table 1. Conditions and results of CNT/polymer microwave welding

\begin{tabular}{|c|c|c|c|c|c|c|}
\hline Year & $\mathrm{CNT}$ & Polymer & $\begin{array}{l}\text { Composite } \\
\text { structure }\end{array}$ & Microwave condition & Result & Ref. \\
\hline 2005 & $\begin{array}{c}\text { MWCNT } \\
\text { (d: } 10 \mathrm{~nm}, 1: 70 \sim 300 \mu \mathrm{m})\end{array}$ & Plexiglas & Sandwich & $\begin{array}{l}2.45 \mathrm{GHz} \\
\text { Below } 1.2 \mathrm{~kW} \\
3 \mathrm{~min}\end{array}$ & Transparent welded polymer & [7] \\
\hline \multirow{2}{*}{2007} & \multirow{2}{*}{$\begin{array}{c}\text { MWCNT } \\
\text { (d: } 30-40 \mathrm{~nm})\end{array}$} & \multirow{2}{*}{$\mathrm{PC}$} & Top layer coating & $\begin{array}{l}2.45 \mathrm{GHz} \\
800 \mathrm{~W} \\
1-10 \mathrm{~s}\end{array}$ & Electrical resistance: $10-50 \Omega /$ square & \multirow{2}{*}{ [8] } \\
\hline & & & Sandwich & $\begin{array}{l}2.45 \mathrm{GHz} \\
200 \mathrm{~W} \\
5-10 \mathrm{~s}\end{array}$ & Fracture load: $35 \mathrm{~N}$ & \\
\hline 2007 & $\begin{array}{c}\text { MWCNT } \\
\text { (d: } 30-40 \mathrm{~nm})\end{array}$ & $\mathrm{PC}$ & Top layer coating & $\begin{array}{l}2.45 \mathrm{GHz} \\
800 \mathrm{~W} \\
1-10 \mathrm{~s}\end{array}$ & $\begin{array}{c}\text { Field emitter } \\
\text { (turn-on voltage: } 0.8 \mathrm{~V} / \mu \mathrm{m} \text { ) }\end{array}$ & [9] \\
\hline 2009 & $\begin{array}{c}\text { SWCNT } \\
\text { (TOP NANOSYS Inc.) }\end{array}$ & $\begin{array}{l}\text { PC } \\
\text { PET }\end{array}$ & Top layer coating & $\begin{array}{l}2.45 \mathrm{GHz} \\
800 \mathrm{~W} \\
10-300 \mathrm{~s}\end{array}$ & $\begin{array}{l}\text { Tensile strength: increasing } 16 \% \\
\text { Displacement: increasing 30\% }\end{array}$ & [10] \\
\hline 2009 & $\begin{array}{c}\text { MWCNT } \\
\text { (d: } 40 \mathrm{~nm}, 1: 10 \mu \mathrm{m})\end{array}$ & PMMA & Powder mixture & $\begin{array}{l}2.45 \mathrm{GHz} \\
700 \mathrm{~W} \\
\text { Up to } 1 \mathrm{~min}\end{array}$ & $\begin{array}{l}\text { Microhardness: } 0.4 \mathrm{GPa} \\
\text { Young's modulus: } 5.6 \mathrm{GPa} \\
\text { Electrical resistivity: } 11 \times 10^{3} \Omega\end{array}$ & [11] \\
\hline 2011 & $\begin{array}{c}\text { MWCNT } \\
\text { (d: } 15 \mathrm{~nm} \text { [12], 1: } 300 \mu \mathrm{m})\end{array}$ & $\mathrm{PE}$ & $\begin{array}{l}\text { Top layer coating } \\
\text { Sandwich }\end{array}$ & $\begin{array}{l}2.45 \mathrm{GHz} \\
750 \mathrm{~W} \\
5-150 \mathrm{~s}\end{array}$ & $\begin{array}{c}\text { Bond strength: } 9.66 \mathrm{MPa} \\
\text { Surface resistance: below } 10^{3} \Omega\end{array}$ & [13] \\
\hline 2012 & $\begin{array}{c}\text { MWCNT } \\
\text { (d: 10-15 nm, 1: } 10-20 \mu \mathrm{m})\end{array}$ & PP & Powder mixture & $\begin{array}{l}2.45 \mathrm{GHz} \\
850 \mathrm{~W} \\
\text { Up to } 50 \mathrm{~s}\end{array}$ & $\begin{array}{l}\text { Electrical resistivity: } 10 \Omega \cdot \mathrm{cm} \\
\text { Fracture load: } 170 \mathrm{~N}\end{array}$ & [14] \\
\hline 2012 & $\begin{array}{c}\text { SWCNT } \\
\text { (nano solutions) }\end{array}$ & $\mathrm{PC}$ & Top layer coating & $\begin{array}{l}2.45 \mathrm{GHz} \\
\mathrm{Up} \text { to } 50 \mathrm{~W} \\
0-15 \mathrm{~s}\end{array}$ & $\begin{array}{l}\text { Welding without distortion } \\
\text { CNT passivation from humidity }\end{array}$ & [15] \\
\hline
\end{tabular}

CNT: carbon nanotube, MWCNT: multi-wall CNT, SWCNT: single-wall CNT, PC: polycarbonate, PET: poly(ethylene terephthalate), PMMA: poly(methyl methacrylate), PE: polyethylene, PP: polypropylene.

bulk polymer [8]. Han et al. [15] showed an obvious difference between microwave and conventional heating with SWCNTs on polycarbonate. In contrast to conventional heat treatment, microwave welding showed no distortion even when the surface temperature measured about $180^{\circ} \mathrm{C}$ (Fig. 5.). Another advantage is the convenience in fabrication. Controlling the layer number or arrangement of CNTs [13] and fabricating CNT-polymer composites with homogeneous distribution $[11,14]$ are much easier because the polymer does not pass through overall melting. Details including experimental conditions and the results are summed up in Table 1.

Other applications like annealing, regeneration and detection based on the microwave heating of CNTs have also been reported.

A rapid temperature elevation and nanotube reconstruction had already been reported by Imholt et al. [6] in 2003. Much more detailed analyses were made by Lin et al. [17] in 2010. After $3 \mathrm{~min}$ of microwave irradiation, the thermal stability, mechanical property, and electrical property of CNTs were improved and the $\mathrm{D} / \mathrm{G}$ ratio of CNTs was decreased.

Wang et al. [18] reported microwave regeneration of CNTs exhausted with dye. By the residual deposits created by microwave irradiation, specific surface area and pore volume were de- (a)
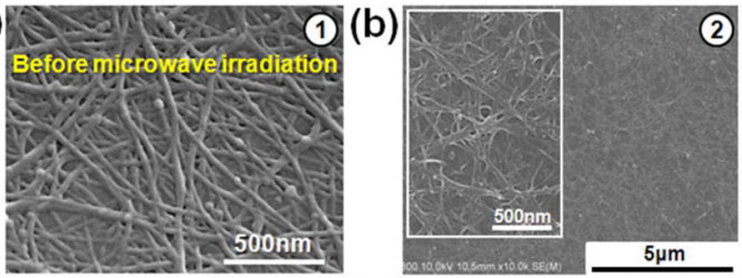

(c)
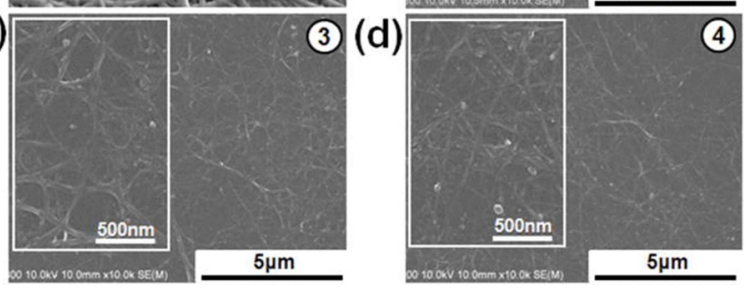

Fig. 5. Scanning electron microscope images of microwave welded single-wall carbon nanotube films (a) before and after microwave irradiation for (b) 7, (c) 9, or (d) $12 \mathrm{~s}$ at $40 \mathrm{~W}$ [15].

Reprinted with permission from [15]. Copyright @ 2012, AIP Publishing LLC.

creased about $25 \%$ after four cycles of adsorption-regeneration process, but the adsorption capacity of the CNTs was $92.8 \%$ of the value of original CNTs after four cycles. 
Table 2. Microwave exfoliation conditions for GICs

\begin{tabular}{cccc} 
Year & Intercalant & Microwave condition & Ref. \\
\hline 2003 & $\mathrm{SO}_{3}$ & $2.45 \mathrm{GHz} / 5 \mathrm{~min}$ & {$[21]$} \\
\hline 2005 & $\mathrm{~K}, \mathrm{Cs}, \mathrm{NaK}_{2}$ & $2.45 \mathrm{GHz} / 1150 \mathrm{~W} / 5-60 \mathrm{~s}$ & {$[22]$} \\
\hline 2005 & $\mathrm{H}_{2} \mathrm{SO}_{4}$ & $2.45 \mathrm{GHz} / 500-1000 \mathrm{~W} / 40 \mathrm{~s}$ & {$[23]$} \\
\hline 2007 & $\mathrm{~K}, \mathrm{THF}$ & - & {$[24]$} \\
\hline 2009 & $\mathrm{HNO}_{3}$ & $2.45 \mathrm{GHZ} / 700 \mathrm{~W} / 60 \mathrm{~s}$ & {$[25]$} \\
\hline 2009 & $\mathrm{H}_{2} \mathrm{SO}_{4}$ & $2.45 \mathrm{GHz} / 750 \mathrm{~W} / 10 \mathrm{~s}$ & {$[26]$} \\
\hline 2010 & $\mathrm{H}_{2} \mathrm{SO}_{4}$ & $2.45 \mathrm{GHz} / 750 \mathrm{~W} / 10 \mathrm{~s}$ & {$[20]$} \\
\hline 2010 & $\left(\mathrm{NH}_{4}\right)_{2} \mathrm{~S}_{2} \mathrm{O}_{8}$ & $2.45 \mathrm{GHz} / 500 \mathrm{~W} / 90 \mathrm{~s}$ & {$[27]$} \\
\hline 2011 & $\mathrm{H}_{2} \mathrm{SO}_{4}, \mathrm{FeCl}_{3}$ & $2.45 \mathrm{GHz} / 450-800 \mathrm{~W} / 30 \mathrm{~s}$ & {$[28]$} \\
\hline 2013 & $\mathrm{HNO}_{3}$ & $2.45 \mathrm{GHz} / 800 \mathrm{~W} / 20 \mathrm{~s}$ & {$[29]$} \\
\hline
\end{tabular}

GICs: graphite intercalation compound, THF: tetrahydrofuran.

Table 3. Specific surface area and expansion volume of EGs prepared by microwave irradiation and pre-heated furnace [28]

\begin{tabular}{cccc}
$\begin{array}{c}\text { Exfoliation } \\
\text { method }\end{array}$ & Condition & $\begin{array}{c}\text { Specific surface } \\
\text { area }\left(\mathrm{m}^{2} / \mathrm{g}\right)\end{array}$ & $\begin{array}{c}\text { Expansion vol- } \\
\text { ume }(\mathrm{mL} / \mathrm{g})\end{array}$ \\
\hline \multirow{2}{*}{ Microwave } & $450 \mathrm{~W}, 30 \mathrm{~s}$ & 63.0 & 305 \\
\cline { 2 - 4 } & $650 \mathrm{~W}, 30 \mathrm{~s}$ & 71.6 & 479 \\
\cline { 2 - 4 } & $850 \mathrm{~W}, 30 \mathrm{~s}$ & 66.6 & 371 \\
\hline Pre-heated furnace & $1100^{\circ} \mathrm{C}, 30 \mathrm{~s}$ & $\sim 50$ & 292 \\
\hline
\end{tabular}

EGs: exfoliated graphite.

Microwave heating was also used for the quantitative detection of CNTs contained in living organisms. Irin et al. [19] reported a technique to match the mass of CNTs injected in Alfalfa root to the temperature change by microwave irradiation. This technique showed a very accurate quantitative detection of CNTs inside a living organism, with an error range below $0.02 \mu \mathrm{g}$.

\section{Microwave Heating of Graphite}

Microwave heating of graphite is mostly related to the preparation of exfoliated graphite from graphite intercalation compound (GIC). Recently, the reduction of graphite oxide (GO) also became a popular topic, with the growing interest in the mass production of graphene.

Rapid heating and the use of a pre-heated furnace are wellknown methods for the exfoliation of GIC. Recently, heating methods using the rapid heating characteristic of microwaves have been reported. (Microwave exfoliation conditions for GICs are summarized in Table 2.)The most notable features of microwave exfoliation are immediacy and effectiveness. The exfoliation is completed within a minute in most cases [23,25-29], and higher volume expansion is observed than with the conventional method using an electrical furnace at over $1000^{\circ} \mathrm{C}[25,28]$ (Table 3 ). In addition, relatively uniform expansion [21], dry-

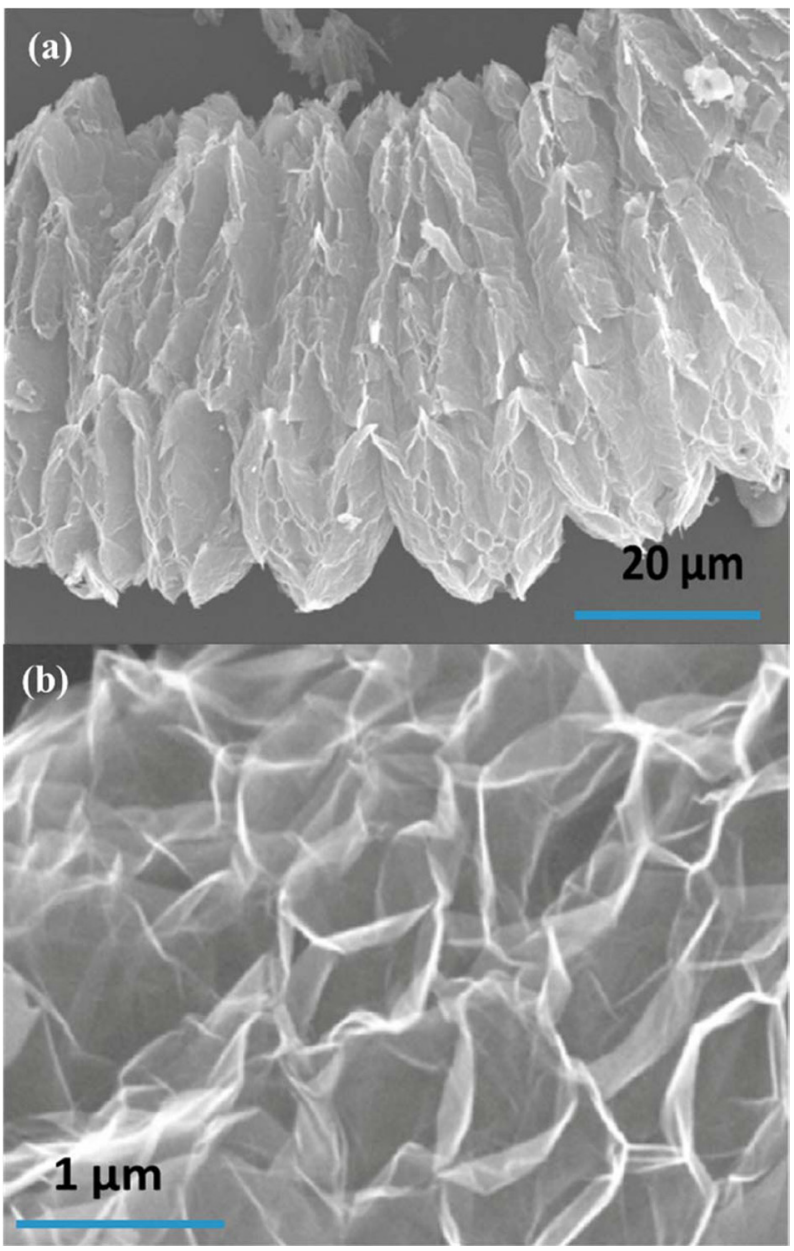

Fig. 6. Scanning electron microscope images of exfoliated graphite by microwave exfoliation method [20].

Reprinted with permission from [20]. Copyright ๑ 2010, Elsevier.

ing effect [22], and the potential of scale-up [20] were reported. Scanning electron microscope images of microwave-exfoliated graphite by Sridhar et al. are shown in Fig. 6.

Similar to the exfoliation of GIC, the reduction of GO requires thermal annealing at over $1000^{\circ} \mathrm{C}$. So, microwave heating has received attention as an efficient heating method. Li et al. [30], heated $\mathrm{GO}$ by microwave at over $400^{\circ} \mathrm{C}$ within $2 \mathrm{~s}$ and the $\mathrm{D} / \mathrm{G}$ ratio was observed by Raman spectroscopy to have decreased from 1.17 to 2.75 after microwave irradiation. Zhu et al. [31] and Hu et al. [32] reported an increase of $\mathrm{C} / \mathrm{O}$ ratio after the microwave reduction of $\mathrm{GO}$.

\section{Microwave Heating of Other Carbon-Based Materials}

Although large and well-arranged graphitic layers rarely exist, carbon-based materials like activated carbon, carbon fiber and others contain a certain portion of graphitic parts and the portion can be increased by elevating the heat treatment temperature $[33,34]$. Therefore, microwave heating of these carbon- 
Table 4. Applications of microwave heating with activated carbons

\begin{tabular}{ccccc} 
Year & Microwave absorber & Purpose & Microwave condition & Ref. \\
\hline 1995 & Activated carbon & Restoration $\left(\mathrm{NO}_{\mathrm{x}}\right)$ & $2.45 \mathrm{GHz} / 480 \mathrm{~W} / 30 \mathrm{~min}$ & {$[37]$} \\
\hline 1995 & Char & Restoration $\left(\mathrm{NO}_{\mathrm{x}}\right)$ & $2.45 \mathrm{GHz} / 480 \mathrm{~W} / 30 \mathrm{~min}$ & {$[35]$} \\
\hline 1996 & Activated carbon & Restoration $\left(\mathrm{NO}_{\mathrm{x}}\right)$ & $2.45 \mathrm{GHz} / 0-900 \mathrm{~W} / 20 \mathrm{~min}$ & {$[38]$} \\
\hline 1996 & Char & Restoration $\left(\mathrm{NO}_{\mathrm{x}}\right)$ & $2.45 \mathrm{GHz} / 480 \mathrm{~W} / 30 \mathrm{~min}$ & {$[36]$} \\
\hline 1999 & Activated carbon & Restoration $($ Oxygenated functionality) & $2.45 \mathrm{GHz} / 1000 \mathrm{~W} / 0-30 \mathrm{~min}$ & {$[39]$} \\
\hline 1999 & Activated carbon & Restoration $($ Oxygenated functionality) & $2.45 \mathrm{GHz} / 1000 \mathrm{~W} / 5 \mathrm{~min}$ & {$[40]$} \\
\hline 1999 & Activated carbon & Chemical reaction (Phenol) & $2.45 \mathrm{GHz} / 1000 \mathrm{~W} / 0-30 \mathrm{~s}$ & {$[41]$} \\
\hline 2001 & Char & Chemical reaction (NO, SO $)$ & $2.45 \mathrm{GHz} / 0-450 \mathrm{~W}$ & {$[42]$} \\
\hline 2004 & Activated carbon & Restoration Chemical reaction (pentachlorophenol) & $2.45 \mathrm{GHz} / 0-800 \mathrm{~W} / 0-10 \mathrm{~min}$ & {$[43]$} \\
\hline 2004 & Activated carbon & Restoration (phenol) & $2.45 \mathrm{GHz} / \mathrm{Varied} \mathrm{for} \mathrm{fixed} \mathrm{T.} \mathrm{/} \mathrm{4} \mathrm{min}$ & {$[44]$} \\
\hline 2007 & Activated carbon & Restoration (salicylic acid) & $2.45 \mathrm{GHz} / \mathrm{Varied} \mathrm{for} \mathrm{fixed} \mathrm{T.} \mathrm{/} \mathrm{4} \mathrm{min}$ & {$[45]$} \\
\hline 2007 & Activated carbon & Chemical reaction (dye) & $2.45 \mathrm{GHz} / 800 \mathrm{~W} / 2.5 \mathrm{~min}$ & {$[46]$} \\
\hline 2008 & Biomass (waste tea) & Activated carbon preparation & $2.45 \mathrm{GHz} / 900 \mathrm{~W} / 30 \mathrm{~s}$ & {$[47]$} \\
\hline 2008 & Biomass (tobacco stem) & Activated carbon preparation & $2.45 \mathrm{GHz} / 0-700 \mathrm{~W} / 0-60 \mathrm{~min}$ & {$[48]$} \\
\hline
\end{tabular}

based materials is also reported.

Microwave heating of activated carbon, char and biomass are mostly related with adsorbents. Restoration of NOx saturated activated carbon and char was extensively reported in the 1990s [35-38]. Microwave heating restored activated carbon and char effectively with sufficient power in several cycles. Kong and Cha [38] reported regeneration of NOx-saturated char within a minute when the input power was over $300 \mathrm{~W}$. Also, Menendez et al. $[39,40]$ reported restoration of a basic property of activated carbon by removing oxygenated functionalities. The carbon and oxygen contents of oxidized activated carbon were changed from $84.50 \%$ to $97.82 \%$ and from $14.98 \%$ to $1.56 \%$, respectively, after $1.5 \mathrm{~min}$ of microwave irradiation. In addition, the intensity of $\mathrm{OH}$ stretching vibration was decreased from 40 to 19 in the semiquantitative Fourier transform infrared spectroscopy after $1.5 \mathrm{~min}$ of microwave irradiation [39]. Also, a comparison between microwave heating and conventional heating was made [40]. Activated carbon irradiated by $1000 \mathrm{~W}$ of microwave reached over $900^{\circ} \mathrm{C}$ in about a minute, and resulted in higher pore volume and carbon contents after $5 \mathrm{~min}$ than conventional heating at $900^{\circ} \mathrm{C}$ for $3 \mathrm{~h}$. Various reports on the applications of microwave heating with activated carbons are listed in Table 4.

Environmental approaches with a similar concept have been reported around and after 2000. Microwave irradiation of activated carbon for removing organic chemicals, dye and $\mathrm{SO} 2$ was tried [41-46]. Representative strengths included the short time required [41,43-46], porous structure preservability [44] and high regeneration efficiency after many cycles [45]. Recently, conversions of biomass into activated carbon through microwave heating were also reported $[47,48]$.

In addition, Carrott et al. [49] reported changes in the elemental composition and the texture of activated carbon fibers after microwave treatment. Extremely rapid heating of over $800^{\circ} \mathrm{C} /$ min and an increase in carbon contents were observed in most cases as in Fig. 7. Dawei et al. used carbon fiber as a microwave susceptor for the remediation of crude oil contaminated soil [50].

While microwave heating of relatively unordered carbons like coal or coke has been reported [51,52], follow-up studies are required for better understanding.

\section{Key Issues}

As mentioned in the previous sections, microwaves can be a powerful tool for the heating of carbon-based materials, and thus various applications have been reported, though deeper understanding of the heating mechanism is still required for advanced and systematic research. Some of the key issues for the development of microwave heating of carbon-based materials are covered in this section.

\subsection{Heating mechanism}

Antenna theory, which is related to radar or communication, and polarization, which is related to solution heating with microwaves, have been studied relatively well $[1,53]$. In the case of microwave heating of solid materials, however, the mechanism has rarely been studied, especially for carbon-based materials. In the beginning of this review, MWS polarization was mentioned as a theory that explains the microwave heating of carbon-based solid materials, but it requires careful re-examination to be accepted as a formal theory.

MWS polarization arises from the buildup of charges at phase or grain boundaries. The original polarization model was made by Maxwell for conducting sheets in an insulating medium. 
With some modifications by Wagner and Sillars, it can cover various conductor shapes [54]. (See Fig. 8. for clear classification of the models.) Recently, it has also been used for the heating mechanism of carbon-based solids by microwave $[55,56]$, but without careful evaluations.

There are still some reservations about using MWS polarization as a mechanism for microwave heating of carbon-based solid materials. Originally, MWS polarization was derived for a perfect insulating medium containing a small quantity of conductors, so the dielectric loss factor $\left(\varepsilon^{\prime \prime}\right)$ of the continuous medium is ignored, because it is assumed to be perfectly insulating. In addition, the dielectric property $(\varepsilon)$ of the whole is assumed to be the same as that of an insulating medium because the presence of the insulating medium is dominant. However, perfect insulators are rarely found in carbon-based materials. Furthermore, most carbon materials, like CNTs, graphite, carbon fiber and activated carbon, have a high proportion of conductive components. So there is a considerable discrepancy between carbonbased materials and the MWS polarization model.

Another aspect to consider is frequency dependence. MWS polarization is dependent on frequency, like all other polarizations, so it is necessary to examine whether the theory is applicable in the microwave frequency range. As shown in Fig. 9, the parameters related to microwave heating (dielectric loss factor and loss tangent) have their peak values at much lower frequency (about $160 \mathrm{KHz}$ ) than common microwave frequencies $(915$ and $2450 \mathrm{MHz}$ ) when calculated using Wagner's model [54]. There are a few reports which suggest MWS polarization happens in the low-frequency region [57], but no reports about the frequency dependence of MWS polarization with carbon-based materials.

It is true that MWS polarization occurs in electron-rich heterogeneous solids, but regarding MWS polarization as the main

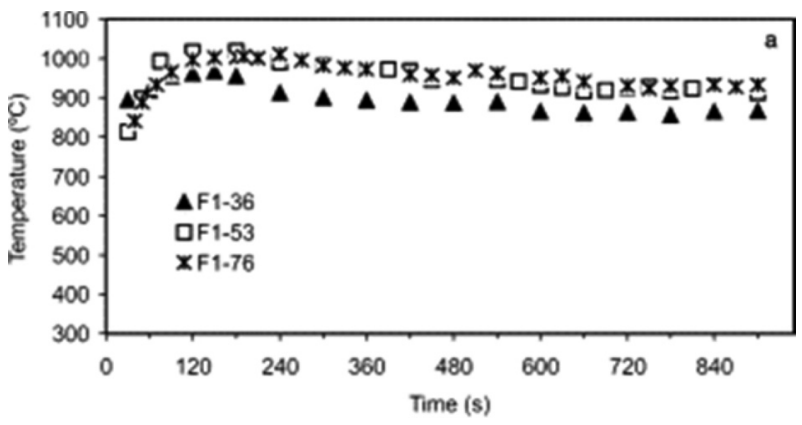

Fig. 7. Temperature profiles depending on the irradiation time during microwave treatment for activated carbon fibers [49]. Reprinted with permission from [49]. Copyright $\odot$ 2001, Elsevier. mechanism for microwave heating of carbon-based solids requires a logical leap. As mentioned above, the basic model of MWS polarization and the features of carbon-based solids are hugely different. Also, additional investigation is required to determine whether the polarization effect is large enough to be considered as a main mechanism for microwave heating of carbon-based solids or not. It is highly recommended to study the true mechanism of microwave heating for carbon-based solids both theoretically and experimentally.

\subsection{Temperature control}

Temperature control is essential for all chemical reactions Both an extremely high heating rate and high temperature (above several hundred degrees Celsius) can be obtained in the microwave heating of carbon-based materials. An extreme heating rate can cause thermal shock, and excessive reaction temperature can cause undesired reactions.

Microwave heating is a result of the absorption of electromagnetic energy by materials. The average power absorbed by a material can be derived from Maxwell's equation and expressed as below,

$$
P_{a v}=2 \pi f \varepsilon_{0} \varepsilon_{e f f}^{\prime \prime} E_{r m s}^{2} V+2 \pi f \mu_{0} \mu_{e f f}^{\prime \prime} H_{r m s}^{2} V
$$

where $f$ refers to frequency, $\varepsilon_{0}$ refers to vacuum permittivity, $\varepsilon_{\text {eff }}^{\prime}$ refers to the effective relative dielectric loss factor, $\mu_{0}$ refers to the permeability of free space, $\mu^{\prime \prime}{ }_{\text {eff }}$ refers to the effective relative magnetic loss factor, $E_{r m s}$ refers to the root mean square of the electric field, $H_{r m s}$ refers to the root mean square of the magnetic field and refers to the volume of material [57].

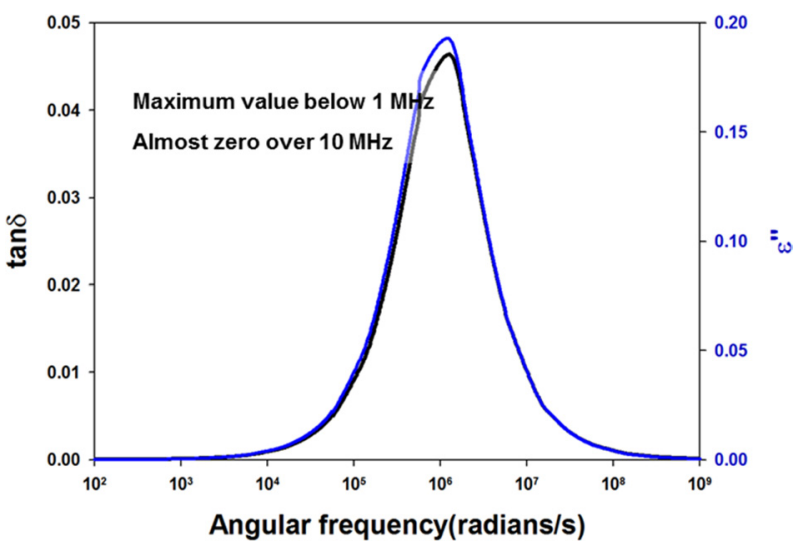

Fig. 9. Loss tangent $(\tan \delta)$ and dielectric loss factor $\left(\varepsilon^{\prime \prime}\right)$ with varying angular frequency calculated by Wagner's model.

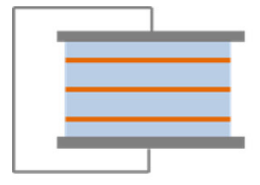

(a) Maxwell's model

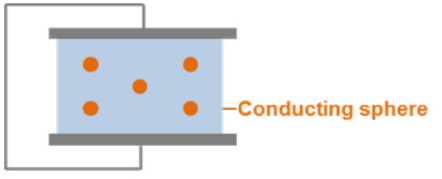

(b) Wagner's model

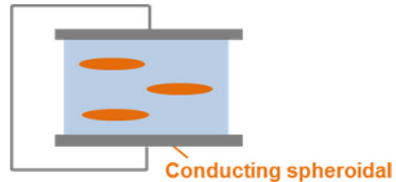

(c) Sillars's model

Fig. 8. Models of inhomogeneous dielectrics employed for analyzing interfacial polarization. (a) Maxwell's model consisting of conducting plane sheets and insulating medium, (b) Wagner's model with conducting spheres and (c) Sillars's model with conducting spheroidals. 
Table 5. Penetration depth of various materials at $915 \mathrm{MHz}$ and 2.45 $\mathrm{GHz}$ [2]

\begin{tabular}{ccc}
\multirow{2}{*}{ Material } & \multicolumn{2}{c}{ Penetration depth of electric field } \\
\cline { 2 - 3 } & $915 \mathrm{MHz}$ & $2.45 \mathrm{GHz}$ \\
\hline Water (distilled, $\left.25^{\circ} \mathrm{C}\right)$ & $76.51 \mathrm{~cm}$ & $2.88 \mathrm{~cm}$ \\
\hline Water $+0.5 \mathrm{M} \mathrm{NaCl}\left(25^{\circ} \mathrm{C}\right)$ & $0.51 \mathrm{~cm}$ & $0.45 \mathrm{~cm}$ \\
\hline Polyethylene & $7839.3 \mathrm{~cm}$ & $5907.1 \mathrm{~cm}$ \\
\hline Polystyrene & - & $7619.3 \mathrm{~cm}$ \\
\hline $\mathrm{Cu}$ & $2.2 \mu \mathrm{m}$ & $1.3 \mu \mathrm{m}$ \\
\hline $\mathrm{Al}$ & $2.7 \mu \mathrm{m}$ & $1.7 \mu \mathrm{m}$ \\
\hline $\mathrm{Ni}$ & $4.4 \mu \mathrm{m}$ & $2.7 \mu \mathrm{m}$ \\
\hline $\mathrm{Fe}$ & $5.2 \mu \mathrm{m}$ & $3.2 \mu \mathrm{m}$ \\
\hline
\end{tabular}

In the above equation, effective dielectric loss factor $\left(\varepsilon^{\prime \prime}{ }_{e f f}\right)$ and effective magnetic loss factor $\left(\mu^{\prime \prime}{ }_{e f f}\right)$ are determined by the material. The frequency of microwave $(f)$ and electric field strength $\left(E_{r m s}\right)$ connected with microwave power are independent variables of microwave heating, and thus can control heating rate and maximum temperature.

In reality, only a limited range of microwave frequencies are allowed to use for microwave heating, to avoid interference with microwave frequencies used for communication purposes. On the other hand, microwave power can be varied without restriction, though there are only a few papers investigating the effect of microwave power $[19,42,43]$. Most researchers have used commercial or domestic microwave ovens, which are made for cooking with a single or a limited power range $[11,13,14,18,20,22,26,28,31,32,41,46-48,50]$. Therefore, these researches are limited inasmuch as they reflect an observed reaction at just one fixed power level, which only gives a consistent heating rate and maximum temperature for a given target material.

\subsection{Penetration depth}

Penetration depth has great importance in the microwave heating of conducting materials. The penetration depth of a field is defined as the distance from the surface to a certain internal point where the magnitude of field strength decreases to 1/e of the original magnitude at the surface [58]. The penetration depth of an electric field is expressed as below,

$$
\mathrm{d}=1 /\left\{2 \pi f\left(\frac{\mu_{0} \mu^{\prime} \varepsilon_{0} \varepsilon^{\prime}}{2}\right)^{1 / 2}\left[\left(1+(\tan \delta)^{2}\right)^{1 / 2}-1\right]^{1 / 2}\right\}
$$

where $\varepsilon^{\prime}$ refers to the relative permittivity, $\mu^{\prime}$ refers to the relative permeability and $\tan \delta$ refers to the loss tangent [2].

In the interior of a material beyond the penetration depth, microwave heating is poor because the field strength of the electromagnetic wave becomes weaker. Table 5 lists the penetration depth of various materials.

In general, microwaves heat a target material more homogeneously than a conventional method since the microwave has

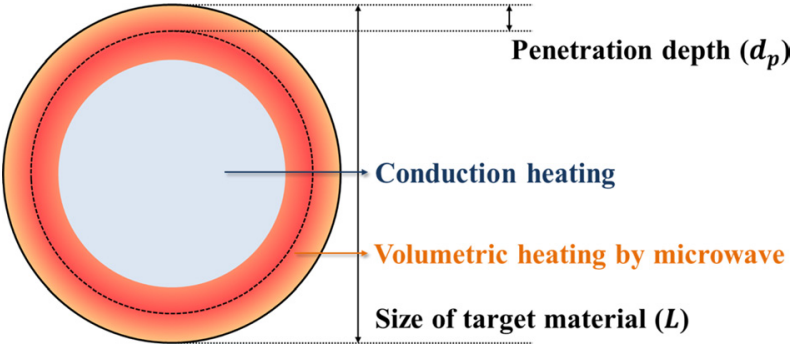

Fig. 10. Schematic illustration of microwave heating phenomenon when the size of target material is much larger than the microwave penetration depth.

penetrative power, so volumetric heating is possible. However, it is not valid in all cases. When the scale of the target material is much larger than the microwave penetration depth, advantages like efficient and homogeneous heating are not applicable because the energy is only absorbed at the surface, as shown in Fig. 10.

Usually, liquids have a centimeter-scale penetration depth, so they can be effectively heated by microwaves by stirring or using a flow reactor. In the case of electron-rich solid systems like metals and carbons, however, penetration depth becomes a critical factor because the penetration depth is only micron-scale. Therefore, reactor design considering the penetration depth is strongly recommended when using microwaves as a heating source for carbon-based solids.

\section{Conclusion}

Microwave heating is a powerful heating method for carbonbased solid materials. In most cases, a temperature of over $1000^{\circ} \mathrm{C}$ is obtained within a few minutes and is easily maintained, so processing time is absolutely shortened. Typical applications for microwave heating of carbon-based solid materials take advantage of the the ease of reaching and maintaining high temperature, and include the exfoliation of graphite, regeneration of carbon adsorbents, and reconstruction of crystalline structure. Furthermore, the selective-heating nature of microwaves is adequate for welding carbon-based materials with polymers.

In this review, various cases of microwave heating of carbonbased solid materials were introduced, including CNTs, graphite, activated carbons and carbon fibers. The diverse advantages of microwave heating are clearly shown experimentally, but deficient understanding about the heating mechanism and in the lack of a systematic approach are sticking points in advanced research.

\section{References}

[1] Kappe CO, Dallinger D, Murphree SS. Practical Microwave Synthesis for Organic Chemists: Strategies, Instruments, and Protocols, Wiley-VCH, Weinheim (2009).

[2] Gupta M, Wong WL. Microwaves and Metals, John Wiley \& Sons, Hoboken, NJ (2007). 
[3] Wallace PR. The band theory of graphite. Phys Rev, 71, 622 (1947). http://dx.doi.org/10.1103/PhysRev.71.622.

[4] Ganguli N, Krishnan KS. The magnetic and other properties of the free electrons in graphite. Proc Royal Soc London Series A Math Phys Sci, 177, 168 (1941). http://dx.doi.org/10.1098/ rspa.1941.0002.

[5] Grimes CA, Mungle C, Kouzoudis D, Fang S, Eklund PC. The 500 $\mathrm{MHz}$ to $5.50 \mathrm{GHz}$ complex permittivity spectra of single-wall carbon nanotube-loaded polymer composites. Chem Phys Lett, 319, 460 (2000). http://dx.doi.org/10.1016/S0009-2614(00)00196-2.

[6] Imholt TJ, Dyke CA, Hasslacher B, Perez JM, Price DW, Roberts JA, Scott JB, Wadhawan A, Ye Z, Tour JM. Nanotubes in microwave fields: light emission, intense heat, outgassing, and reconstruction. Chem Mater, 15, 3969 (2003). http://dx.doi.org/10.1021/ cm034530g.

[7] Zhang M, Fang S, Zakhidov AA, Lee SB, Aliev AE, Williams CD, Atkinson KR, Baughman RH. Strong, transparent, multifunctional, carbon nanotube sheets. Science, 309, 1215 (2005). http://dx.doi. org/10.1126/science.1115311.

[8] Wang CY, Chen TH, Chang SC, Cheng SY, Chin TS. Strong carbon-nanotube-polymer bonding by microwave irradiation. Adv Funct Mater, 17, 1979 (2007). http://dx.doi.org/10.1002/ adfm. 200601011.

[9] Wang CY, Chen TH, Chang SC, Chin TS, Cheng SY. Flexible field emitter made of carbon nanotubes microwave welded onto polymer substrates. Appl Phys Lett, 90, 103111 (2007). http://dx.doi. org/10.1063/1.2711771.

[10] Shim HC, Kwak YK, Han CS, Kim S. Enhancement of adhesion between carbon nanotubes and polymer substrates using microwave irradiation. Scripta Mater, 61, 32 (2009). http://dx.doi. org/10.1016/j.scriptamat.2009.02.060.

[11] Wang H, Feng J, Hu X, Ming Ng K. The formation of hollow poly(methyl methacrylate)/multiwalled carbon nanotube nanocomposite cylinders by microwave irradiation. Nanotechnology, 20, 095601 (2009). http://dx.doi.org/10.1088/0957-4484/20/9/095601.

[12] Zhang X, Jiang K, Feng C, Liu P, Zhang L, Kong J, Zhang T, Li Q, Fan S. Spinning and processing continuous yarns from 4-inch wafer scale super-aligned carbon nanotube arrays. Adv Mater, 18, 1505 (2006). http://dx.doi.org/10.1002/adma.200502528.

[13] Xie R, Wang J, Yang Y, Jiang K, Li Q, Fan S. Aligned carbon nanotube coating on polyethylene surface formed by microwave radiation. Composites Sci Technol, 72, 85 (2011). http://dx.doi. org/10.1016/j.compscitech.2011.10.003.

[14] Wu T, Pan Y, Liu E, Li L. Carbon nanotube/polypropylene composite particles for microwave welding. J Appl Polym Sci, 126, E283 (2012). http://dx.doi.org/10.1002/app.36832.

[15] Han JT, Kim D, Kim JS, Seol SK, Jeong SY, Jeong HJ, Chang WS, Lee GW, Jung S. Self-passivation of transparent single-walled carbon nanotube films on plastic substrates by microwave-induced rapid nanowelding. Appl Phys Lett, 100, 163120 (2012). http:// dx.doi.org/10.1063/1.4704666.

[16] Sahoo NG, Rana S, Cho JW, Li L, Chan SH. Polymer nanocomposites based on functionalized carbon nanotubes. Prog Polym Sci, 35, 837 (2010). http://dx.doi.org/10.1016/j.progpolymsci.2010.03.002.

[17] Lin W, Moon KS, Zhang S, Ding Y, Shang J, Chen M, Wong CP. Microwave makes carbon nanotubes less defective. ACS Nano, 4 , 1716 (2010). http://dx.doi.org/10.1021/nn901621c.

[18] Wang J, Peng X, Luan Z, Zhao C. Regeneration of carbon nano- tubes exhausted with dye reactive red 3BS using microwave irradiation. J Hazard Mater, 178, 1125 (2010). http://dx.doi. org/10.1016/j.jhazmat.2010.01.112.

[19] Irin F, Shrestha B, Cañas JE, Saed MA, Green MJ. Detection of carbon nanotubes in biological samples through microwave-induced heating. Carbon, 50, 4441 (2012). http://dx.doi.org/10.1016/j.carbon.2012.05.022.

[20] Sridhar V, Jeon JH, Oh IK. Synthesis of graphene nano-sheets using eco-friendly chemicals and microwave radiation. Carbon, $\mathbf{4 8}$ 2953 (2010). http://dx.doi.org/10.1016/j.carbon.2010.04.034.

[21] Kwon OY, Choi SW, Park KW, Kwon YB. The preparation of exfoliated graphite by using microwave. J Ind Eng Chem, 9, 743 (2003).

[22] Viculis LM, Mack JJ, Mayer OM, Hahn HT, Kaner RB. Intercalation and exfoliation routes to graphite nanoplatelets. J Mater Chem, 15, 974 (2005). http://dx.doi.org/10.1039/B413029D.

[23] Tryba B, Morawski AW, Inagaki M. Preparation of exfoliated graphite by microwave irradiation. Carbon, 43, 2417 (2005). http:// dx.doi.org/10.1016/j.carbon.2005.04.017.

[24] Falcao EHL, Blair RG, Mack JJ, Viculis LM, Kwon CW, Bendikov M, Kaner RB, Dunn BS, Wudl F. Microwave exfoliation of a graphite intercalation compound. Carbon, 45, 1367 (2007). http:// dx.doi.org/10.1016/j.carbon.2007.01.018.

[25] Wei T, Fan Z, Luo G, Zheng C, Xie D. A rapid and efficient method to prepare exfoliated graphite by microwave irradiation. Carbon, 47, 337 (2009). http://dx.doi.org/10.1016/j.carbon.2008.10.013.

[26] Yu XJ, Wu J, Zhao Q, Cheng XW. Study on the sorption of exfoliated graphite prepared by microwave irradiation. International Conference on Energy and Environment Technology, Guilin, China, 590 (2009). http://dx.doi.org/10.1109/ICEET.2009.610.

[27] Xin G, Hwang W, Kim N, Cho SM, Chae H. A graphene sheet exfoliated with microwave irradiation and interlinked by carbon nanotubes for high-performance transparent flexible electrodes. Nanotechnology, 21, 405201 (2010). http://dx.doi.org/10.1088/ 0957-4484/21/40/405201.

[28] Geng Y, Zheng Q, Kim JK. Effects of stage, intercalant species and expansion technique on exfoliation of graphite intercalation compound into graphene sheets. J Nanosci Nanotechnol, 11, 1084 (2011). http://dx.doi.org/10.1166/jnn.2011.3063.

[29] Chuan XY. Graphene-like nanosheets synthesized by natural flaky graphite in Shandong, China. Int Nano Lett, 3, 1 (2013). http:// dx.doi.org/10.1186/2228-5326-3-6.

[30] Li Z, Yao Y, Lin Z, Moon K-S, Lin W, Wong C. Ultrafast, dry microwave synthesis of graphene sheets. J Mater Chem, 20, 4781 (2010). http://dx.doi.org/10.1039/C0JM00168F.

[31] Zhu Y, Murali S, Stoller MD, Velamakanni A, Piner RD, Ruoff RS. Microwave assisted exfoliation and reduction of graphite oxide for ultracapacitors. Carbon, 48, 2118 (2010). http://dx.doi. org/10.1016/j.carbon.2010.02.001.

[32] Hu H, Zhao Z, Zhou Q, Gogotsi Y, Qiu J. The role of microwave absorption on formation of graphene from graphite oxide. Carbon, 50, 3267 (2012). http://dx.doi.org/10.1016/j.carbon.2011.12.005.

[33] Marsh H. Activated Carbon, Elsevier, Boston, MA (2006).

[34] Donnet JB. Carbon Fibers. 3rd ed., Marcel Dekker, New York, NY (1998).

[35] Cha CY, Kong Y. Enhancement of $\mathrm{NO}_{\mathrm{x}}$ adsorption capacity and rate of char by microwaves. Carbon, 33, 1141 (1995). http://dx.doi. org/10.1016/0008-6223(95)00066-M.

[36] Kong Y, Cha CY. Reduction of $\mathrm{NO}_{\mathrm{x}}$ adsorbed on char with micro- 
wave energy. Carbon, 34, 1035 (1996). http://dx.doi.org/10.1016/ 0008-6223(96)00051-6.

[37] Kong Y, Cha CY. $\mathrm{NO}_{\mathrm{x}}$ abatement with carbon adsorbents and microwave energy. Energy Fuels, 9, 971 (1995). http://dx.doi.org/ 10.1021/ef00054a006

[38] Kong Y, Cha CY. Microwave-induced regeneration of $\mathrm{NO}_{\mathrm{x}}$-saturated char. Energy Fuels, 10, 1245 (1996). http://dx.doi.org/10.1021/ ef960060j.

[39] Menéndez JA, Menéndez EM, Iglesias MJ, García A, Pis JJ. Modification of the surface chemistry of active carbons by means of microwave-induced treatments. Carbon, 37, 1115 (1999). http:// dx.doi.org/10.1016/S0008-6223(98)00302-9.

[40] Menéndez JA, Menéndez EM, García A, Parra JB, Pis JJ. Thermal treatment of active carbons: a comparison between microwave and electrical heating. J Microw Power Electromagn Energy, 34, 137 (1999).

[41] Tai HS, Jou CJG. Application of granular activated carbon packed-bed reactor in microwave radiation field to treat phenol. Chemosphere, 38, 2667 (1999). http://dx.doi.org/10.1016/S00456535(98)00432-9.

[42] Cha CY, Kim DS. Microwave induced reactions of sulfur dioxide and nitrogen oxides in char and anthracite bed. Carbon, 39, 1159 (2001). http://dx.doi.org/10.1016/S0008-6223(00)00240-2.

[43] Liu X, Quan X, Bo L, Chen S, Zhao Y. Simultaneous pentachlorophenol decomposition and granular activated carbon regeneration assisted by microwave irradiation. Carbon, 42, 415 (2004). http:// dx.doi.org/10.1016/j.carbon.2003.12.032.

[44] Ania CO, Menéndez JA, Parra JB, Pis JJ. Microwave-induced regeneration of activated carbons polluted with phenol. A comparison with conventional thermal regeneration. Carbon, 42, 1383 (2004). http://dx.doi.org/10.1016/j.carbon.2004.01.010.

[45] Ania CO, Parra JB, Menéndez JA, Pis JJ. Microwave-assisted regeneration of activated carbons loaded with pharmaceuticals. Water Res, 41, 3299 (2007). http://dx.doi.org/10.1016/j.watres.2007. 05.006 .

[46] Zhang Z, Shan Y, Wang J, Ling H, Zang S, Gao W, Zhao Z, Zhang $\mathrm{H}$. Investigation on the rapid degradation of congo red catalyzed by activated carbon powder under microwave irradiation. J Hazard Mater, 147, 325 (2007). http://dx.doi.org/10.1016/j. jhazmat.2006.12.083.

[47] Yagmur E, Ozmak M, Aktas Z. A novel method for production of activated carbon from waste tea by chemical activation with microwave energy. Fuel, 87, 3278 (2008). http://dx.doi.org/10.1016/j. fuel.2008.05.005.

[48] Li W, Zhang LB, Peng JH, Li N, Zhu XY. Preparation of high surface area activated carbons from tobacco stems with $\mathrm{K}_{2} \mathrm{CO}_{3}$ activation using microwave radiation. Ind Crops Prod, 27, 341 (2008). http://dx.doi.org/10.1016/j.indcrop.2007.11.011.

[49] Carrott PJM, Nabais JMV, Ribeiro Carrott MML, Menéndez JA. Thermal treatments of activated carbon fibres using a microwave furnace. Microporous Mesoporous Mater, 47, 243 (2001). http:// dx.doi.org/10.1016/S1387-1811(01)00384-5.

[50] Li D, Zhang Y, Quan X, Zhao Y. Microwave thermal remediation of crude oil contaminated soil enhanced by carbon fiber. J Environ Sci (China), 21, 1290 (2009). http://dx.doi.org/10.1016/S10010742(08)62417-1.

[51] Lester E, Kingman S. The effect of microwave pre-heating on five different coals. Fuel, 83, 1941 (2004). http://dx.doi.org/10.1016/j. fuel.2004.05.006.

[52] Lester E, Kingman S, Dodds C, Patrick J. The potential for rapid coke making using microwave energy. Fuel, 85, 2057 (2006). http://dx.doi.org/10.1016/j.fuel.2006.04.012.

[53] Silver S. Microwave Antenna Theory and Design, P. Peregrinus on behalf of the Institution of Electrical Engineers, London, UK (1984).

[54] Sillars RW. The properties of a dielectric containing semiconducting particles of various shapes. J Inst Electr Eng, 80, 378 (1937).

[55] Menéndez JA, Arenillas A, Fidalgo B, Fernández Y, Zubizarreta L, Calvo EG, Bermúdez JM. Microwave heating processes involving carbon materials. Fuel Process Technol, 91, 1 (2010). http://dx.doi. org/10.1016/j.fuproc.2009.08.021.

[56] Nabais JMV, Carrott PJM, Carrott MMLR, Padre-Eterno AM, Menéndez JA, Dominguez A, Ortiz AL. New acrylic monolithic carbon molecular sieves for $\mathrm{O}_{2} / \mathrm{N}_{2}$ and $\mathrm{CO}_{2} / \mathrm{CH}_{4}$ separations. Carbon, 44, 1158 (2006). http://dx.doi.org/10.1016/j.carbon.2005.11.005.

[57] Metaxas AC, Meredith RJ. Industrial Microwave Heating. Reprinted with minor corrections, 1988 ed., P. Peregrinus on behalf of the Institution of Electrical Engineers, London, UK (1988).

[58] Metaxas AC. Foundations of Electroheat: A Unified Approach, John Wiley and Sons, New York, NY (1996). 